\title{
O PROCESSO DE ALFABETIZAÇÃO E LETRAMENTO DOS ALUNOS DA EJA: UM OLHAR ATENTO ÀS DIFERENÇAS
}

\section{THE LITERACY PROCESS OF THE EJA STUDENTS: A CAREFULL LOOK AT THE DIFFERENCES}

Micleiton dos Santos Hilario ${ }^{1}$

Samira Casagrande ${ }^{2}$

\begin{abstract}
RESUMO: Suscitar uma discussão nos meios educacionais e não educacionais sobre a Educação de Jovens e Adultos é urgente e fundamental. Mesmo que se tenha a consciência da obrigatoriedade da educação, uma parcela da população ainda é excluída do sistema regular de ensino e da sociedade, pois o analfabeto sofre com atitudes preconceituosas nas práticas sociais. Optou-se por este tema por considerá-lo de extrema importância aos olhos de quem acredita e luta por uma educação justa e igualitária e ainda por não ser uma questão muito explícita na sociedade. Assim, trazer a problemática a ser pensada na situação em que se encontram os alunos da EJA na sociedade torna-se imprescindível. A metodologia escolhida para este estudo é a pesquisa de campo com um roteiro composto de cinco perguntas, com o objetivo geral de analisar como os alunos da EJA se percebem alfabetizados e letrados dentro de suas diferenças. Este trabalho traz pontos de discussão teórica a respeito das dificuldades, preconceito e a alfabetização e letramento dos alunos jovens e adultos, mostrando como se perceberam alfabetizados com suas especificidades e como enfrentaram o preconceito ao voltarem à escola depois de anos. Em suma, a partir das leituras e da pesquisa feita com os pesquisados pode-se perceber que, mesmo com tantas dificuldades e desafios os impedindo de seguir em busca dos seus objetivos, os alunos se mostraram vitoriosos e provaram que é possível se alfabetizar dentro de suas diferenças.
\end{abstract}

PALAVRAS-CHAVE: Educação de jovens e adultos. Alfabetização e letramento. Preconceito.

ABSTRACT: Raising a discussion in educational and non-educational settings on Youth and Adult Education is urgent and fundamental. Even if one is aware of the obligation of education, a portion of the population is still excluded from the regular system of education and society, because the illiterate suffers from prejudiced attitudes in social practices. This theme was chosen as extremely important in the eyes of those who believe in and strive for a just and equal education and yet not be a very explicit issue in society. Thus, bringing the

\footnotetext{
${ }^{1}$ Acadêmico formando do Curso de Pedagogia pela Universidade do Extremo Sul Catarinense - UNESC. Email: micleiton.is@gmail.com.

${ }^{2}$ Professora Mestre em Educação pela Universidade do Extremo Sul Catarinense - UNESC. Email: sca@unesc.net.

Saberes Pedagógicos, Criciúma, v. 3, n³, Edição Especial 2019.- Curso de Pedagogia - UNESC
} 


\section{SABERES PEDAGÓGICOS}

Revista do Curso de Graduaçāo de Pedagogia - Unesc

ISSN 2526-4559

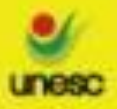

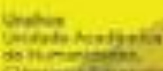

bing

problematic to be thought of in the situation that the students of the EJA in the society are, becomes essential. The methodology chosen for this study is the field research with a script composed of five questions, with the general objective of analyzing how the students of the EJA perceive themselves to be literate and literate within their differences. This work brings up points of theoretical discussion about the difficulties, prejudice and literacy and literacy of young and adult students, showing how they perceived themselves as literate with their specificities and how they faced prejudice when they returned to school after years. In short, from the readings and the research done with the respondents, it can be seen that, even with so many difficulties and challenges preventing them from pursuing their objectives, the students have proved themselves victorious and proved that it is possible to become literate within their differences.

KEYWORDS: Youth and Adult Education. Literacy. Prejudice.

\section{INTRODUÇÃO}

A sociedade ainda é muito preconceituosa, seja com o negro, pessoa com deficiência, homossexual e com a própria mulher. Com a educação de jovens e adultos também não é diferente, boa parte da população rotula esses alunos, como se não tivessem direitos por serem analfabetos e iletrados. São pessoas que não tiveram a oportunidade de frequentar a escola na idade certa, e, por consequência disso, não podem desfrutar de alguns dos seus direitos como cidadãos.

Partindo disso, surge a escolha do tema: "O processo de alfabetização e letramento dos alunos da EJA: um olhar atento às diferenças", para ter a visão de como os alunos lidam com as diferenças encontradas na turma, quais sejam: alunos que não sabem ler e escrever, diferentes níveis no processo de alfabetização e letramento e divergência entre as idades.

Neste contexto, a problemática desta pesquisa é: os alunos da EJA se percebem alfabetizados e letrados dentro de suas diferenças? O estudo apresenta como objetivo geral analisar como os alunos da EJA se percebem alfabetizados e letrados dentro de suas diferenças. Os objetivos específicos ficaram assim elencados: conhecer os preconceitos sofridos pelos alunos da EJA; identificar as facilidades e dificuldades encontradas pelos alunos nos seus processos de alfabetização e letramento e perceber de que formas os alunos da EJA se sentem incluídos nas práticas sociais.

Saberes Pedagógicos, Criciúma, v. 3, n³, Edição Especial 2019.- Curso de Pedagogia - UNESC 
A metodologia usada foi uma pesquisa de campo, em uma escola municipal localizada na cidade de Criciúma/SC, com sete alunos, sendo três do sexo masculino e quatro do sexo feminino, em que foi feito um roteiro com cinco perguntas para obter os resultados.

O artigo está dividido em 03 títulos, sendo eles: o que é analfabetismo, alfabetização e letramento? Nessa etapa se apresenta de forma breve, mas detalhada, o que significa cada classificação dessas. O título seguinte aborda o preconceito enfrentado pelos analfabetos, com os desafios que os alunos enfrentaram ao voltar à escola e que ainda enfrentam para conseguir se alfabetizar, e por último EJA: uma exclusão social, trazendo aspectos sobre a necessidade de acolhimento que a escola precisa tomar para tornar os alunos da EJA realmente inclusos no sistema escolar. Logo após, apresenta-se o resultado, que foi analisado a partir do referencial teórico, e por último a conclusão desta pesquisa.

\section{O QUE É ANALFABETISMO, ALFABETIZAÇÃO E LETRAMENTO?}

No começo do século XX, começaram a utilizar e expandir as palavras: "analfabeto" (é o sujeito que ainda não aprendeu a ler e escrever ou foi reprovado no primeiro ano escolar); "analfabetismo" (o estado ou condição do analfabeto); "alfabetização" (ato ou efeito de alfabetizar, ensinar na escola a ler e escrever os analfabetos); "alfabetizado" (aquele que aprendeu a ler e escrever, ou seja, aprovado no primeiro ano escolar). Inserida em uma campanha contra o analfabetismo, a alfabetização da população passou a ser entendida com toda a sua força política e potencialmente nacionalizadora, relacionada com a noção de "educação popular" e com a necessidade da eficiência da escola, medida pelo número de matrículas e aprovações no primeiro ano (MORTATTI, 2004). Nesse sentido, a mesma autora, apoiada nas ideias de Paulo Freire destaca:

[...] os sentidos das palavras 'alfabetização', 'alfabetizado', 'analfabetismo', 'analfabeto' se alargaram, passando a abranger questões relacionadas não apenas à aquisição do código escrito em situação escolar, mas também à 'leitura do mundo' e, em decorrência, a uma participação mais consciente de cada cidadão na transformação da realidade política, social, cultural brasileira. (2004, p. 68) 
Em virtude disso, o analfabetismo é o estado ou condição que se encontra o analfabeto, ou seja, é aquele que não conhece o alfabeto, consequentemente, não sabe ler e escrever e não faz o usa da leitura e escrita. (SOARES, 2003).

Adotando-se este ponto de vista, entende-se a estreita ligação da alfabetização com a escolaridade e que, portanto, o alfabetizado é aquele que vive nas condições ou estado de quem sabe ler e escrever e a escolarização está inteiramente ligada a essa prática. Mas em meio a essa discussão destacamos que nem todos os alfabetizados são letrados, havendo uma diferença entre alfabetização e letramento. $\mathrm{O}$ alfabetizado é o sujeito que tem as habilidades da leitura e escrita, mas muitas vezes não se aprimora, enquanto o letrado consegue fazer a decodificação da palavra escrita, compreendendo o seu significado e incorporando-a nas práticas sociais (SOARES, 2003).

Com isso, Soares (2003, p. 38) enfatiza que "a hipótese é que aprender a ler e a escrever e, além disso, fazer o uso da leitura e da escrita transformam o indivíduo, leva o indivíduo a outro estado ou condição sob vários aspectos: sociais, culturais, cognitivos, linguísticos, entre outros." Ou seja, passam a ter, sentir, nomear e transformar a visão do mundo em que vivem.

O letramento, ainda não é encontrado no dicionário por ter uma complexidade muito grande. $\mathrm{O}$ fato de um adulto ou uma criança saber ler e escrever não os tornam letrados, mas sim alfabetizados e quanto maior o nível de escolarização, maior o grau de letramento e quanto menor o nível de escolarização, menor o grau de letramento. (KLEIMAN, 1995). Diante disso, o letramento tem por definição a capacidade de se aprimorar da língua escrita, ou seja, decodificar o que está lendo ou ouvindo e saber utilizar nas práticas sociais. (SOARES, 2003).

É sob este ponto de vista que, pode-se afirmar que passamos a enfrentar uma nova realidade social em que não basta apenas saber ler e escrever, é preciso também fazer o uso do ler e escrever, saber responder às exigências da sociedade. Partindo daí, surge o termo letramento (MORTATTI, 2004). Para a referida autora (2004, p. 98) grafocêntricas, isto é, sociedades organizadas em torno de um sistema de escrita e em que esta, sobretudo por meio do texto escrito e impresso, assume importância

Saberes Pedagógicos, Criciúma, v. 3, n³3, Edição Especial 2019.- Curso de Pedagogia - UNESC 
central na vida das pessoas e em suas relações com os outros e com o mundo em que vivem.

Sendo assim, o processo de alfabetização e letramento não acontece sem a leitura e escrita, em que o aluno consiga interpretar o mundo a sua volta de forma representativa e ativa para sua formação. Com isso, ler e escrever não são tarefas fáceis, que o aluno é capaz de aprender do dia para a noite, leva-se tempo e no ritmo dele, para que o objetivo seja alcançado. Segundo Soares (2003, p. 36), “[...] quem aprende a ler e a escrever e passa a usar a leitura e a escrita, a envolver-se em práticas de leitura e de escrita, torna-se uma pessoa diferente, adquire outro estado, outra condição."

Dessa forma, percebe-se que as duas categorias, leitura e escrita, se completam. A leitura é o processo de relacionar símbolos escritos com os sons das letras e de interpretar os textos escritos, pois leitura está associada às habilidades de decodificar e compreender textos escritos. Assim como a escrita que é uma forma de organizar e expressar ideias em língua escrita, transmitindo significado ao leitor. Ambas são habilidades linguísticas e psicológicas. (SOARES, 2003).

Posto isso, segundo Mortatti (2004), o processo de alfabetização, muitas vezes, pode ser longo. Mas isso não é o suficiente para dizer que a pessoa alfabetizada é letrada, e só por viver em uma sociedade, supostamente, letrada não garante a participação igualitária na cultura escrita. Assim como a tecnologia, onde o ler e escrever em busca do conhecimento também não está disponível para todos. Ou seja, além dos recursos, as funções da leitura e escrita, distribuição e utilização do material escrito e impresso dependem do tipo de sociedade e dos projetos políticos, sociais e culturais em determinado momento histórico.

\subsection{O preconceito enfrentado pelos analfabetos}

Em 2003 foi criado o Programa Brasil Alfabetizado pelo MEC (Ministério da Educação) "para promover o acesso à educação como um direito de todos, em qualquer momento da vida". Em 2009, o programa estava presente em 3.894 municípios brasileiros com dois objetivos: preparar alfabetizadores e alfabetizar jovens de 15 anos ou mais, que não tiveram oportunidade de concluir seus estudos na idade certa. O público-alvo do programa Saberes Pedagógicos, Criciúma, v. 3, n³, Edição Especial 2019.- Curso de Pedagogia - UNESC 
eram as populações indígenas, rurais, pescadores, pais de crianças beneficiárias do Programa de Erradicação do Trabalho Infantil, pessoas com necessidades especiais, população carcerária e jovens cumprindo medidas socioeducativas (CARVALHO, 2009).

No Brasil, em 2016, a taxa de analfabetismo da população de 15 anos ou mais de idade foi estimada em 7,2\%, ou seja, 11,8 milhões de analfabetos, segundo Pesquisa do IBGE/ 2017. As razões podem ser o trabalho precoce nas lavouras, as dificuldades de acesso, a ausência de escolas na zona rural e outros, que impedem ou limitam os estudos dessas pessoas que ainda não concluíram a sua escolaridade (GALVÃO; PIERRO, 2012). Portanto, os alunos da EJA são aqueles que não tiveram tempo para se dedicar aos estudos enquanto frequentavam a escola. Diferente das crianças que iniciaram os estudos desde cedo, esses alunos tiveram seus motivos para abandonar a escola, mas, mesmo com a experiência de vida que carregam, retornam em busca do aprender.

Como resultado, a leitura e escrita passam a ser consideradas supérfluas mediante a necessidade que possuem momentaneamente. Quando começam a trabalhar, buscam por trabalho pesado, de pouca remuneração, em virtude de saberem que outras profissões de maior prestígio social exigem o domínio da leitura e escrita, e sofrem muitos preconceitos por conta disso. Mas aqueles que sabem pelo menos assinar seu nome se orgulham desta façanha.

No contexto urbano letrado, a impressão da digital se torna a marca evidente do estigma de inferioridade atribuído ao analfabeto e as situações públicas passam a ser vividas como humilhação. Por esse motivo, a assinatura - o desenho do nome - é a primeira aprendizagem aspirada por qualquer adulto em processo de alfabetização. (GALVÃO; PIERRO, 2012, p. 23-24).

Dessa forma, o analfabeto se sente constrangido com as situações enfrentadas diariamente e tem sua autoestima abalada. Assume um lugar, visto pela sociedade, de "escuridão", achando-o ignorante e/ou com algum tipo de deficiência, por não enxergar a sua própria escrita e não saber ler e escrever (GALVÃO; PIERRO, 2012).

Por outro lado, nem todas as pessoas analfabetas se sentem inferiorizadas. Há quem permanece com suas origens e os conhecimentos passados pelos seus pais e pelos aprendizados obtidos na zona rural, fruto de trabalho árduo na lavoura e de sustento de sua família, e sentem orgulho disso (GALVÃO; PIERRO, 2012). 
Sendo assim, são muitas as afirmações que o problema do "atraso" da sociedade brasileira é por conta do analfabetismo. Como também o subdesemprego, violência, tráfico de drogas, dentre outros, são explicados a partir das baixas taxas de escolarização da população brasileira. Mas essa associação entre o analfabetismo e o desenvolvimento social e econômico acontece em muitos países, não apenas no Brasil (GALVÃO; PIERRO, 2012).

Para Souza (2012), a palavra analfabetismo, no Brasil, sempre esteve ligada a termos negativos. Este pensamento é transmitido através da mídia, especialmente na televisão e internet. Muitas gravações são feitas com teor humorístico, mas não levam em consideração a exclusão de direitos que carregam as pessoas que não tiveram e ainda não têm acesso à educação. Por consequência disso, o preconceito afeta a vida dos analfabetos, não conseguindo se expressar em público por medo de falar errado.

A depressão é uma das doenças que atinge os analfabetos, que sonham com uma vida melhor nas cidades grandes, mas que se trancam dentro de casa, presas ao não conhecimento. Esse descaso com os analfabetos não é pauta para muitos debates, por não serem vistos pela sociedade, não se fala abertamente sobre o assunto, como no caso do preconceito racial. Além disso, sentem-se constrangidos ao sair de casa para ir ao supermercado ou no banco, pois não identificam as placas e quando têm que assinar algum documento usam a digital, fato ainda mais constrangedor (SOUZA, 2012).

O preconceito contra o analfabeto é um atentado moral e intelectual, pois, em muitos casos, fazem a ligação da pessoa que não tem uma instrução escolar e/ou não sabe ler e escrever com ausência de inteligência ou incapacidade para saber o que é certo e errado (SOUZA, 2012).

Souza (2012) comenta que, o governo com intuito de minimizar o analfabetismo no Brasil investiu nos cursos noturnos de Educação para Jovens e Adultos. Mas não levou em conta a qualidade do ensino ofertado para os alunos, pois é uma formação compacta. Por outro lado, para os analfabetos era a chance que precisavam para aprender a ler e escrever. Mesmo assim, o caso não é comentado nos círculos familiares e/ou de amizade por vergonha do que vão falar, sendo que a iniciativa do governo foi para diminuir as taxas de analfabetismo no Brasil, deste modo, não queriam ser apontados como analfabetos. 
Em meio a tantas informações, Galvão; Pierro (2012) dizem que a mídia pouco fala dos analfabetos em suas reportagens, fazendo uma exclusão educacional dos jovens e adultos. Uma pesquisa realizada em 2004 levantou dados que 1,8\% das matérias publicadas na imprensa é referente aos alunos da EJA. Sendo assim, o preconceito ainda acompanha a sociedade e exclui os jovens e adultos analfabetos. De certa forma, a mídia está trazendo dados alarmantes sobre o caso, mas ao mesmo tempo são deixados de lado por falta de informações, trazendo dados desvalorizando a educação, a mesma que muitos alunos da Educação de Jovens e Adultos almejam.

\subsection{EJA: uma inclusão social}

Ainda em meio ao século XXI encontramos exclusão em muitos espaços sociais. Infelizmente, um deles é a escola, onde os alunos são excluídos por terem alguma deficiência ou dificuldade de aprendizagem e o olhar preconceituoso sobressai em meio a qualquer outro aspecto. Percebe-se que a inclusão está acontecendo vagarosamente e muitas vezes esses alunos são deixados de lado pela sociedade como algo incomum e/ou jamais vivida. $\mathrm{O}$ pior acontece quando uma pessoa não é alfabetizada e letrada e se isola em "seu mundo" com medo dos olhares e julgamentos das pessoas alfabetizadas e letradas (ROJO, 2009).

A inclusão social não é uma tarefa fácil e por muitos motivos ela não é praticada, ou seja, a exclusão acontece naturalmente.

\footnotetext{
A exclusão escolar manifesta-se das mais diversas e perversas maneiras, e quase sempre o que está em jogo é a ignorância do aluno diante dos padrões de cientificidade do saber. Ocorre que a escola se democratizou, abrindo-se a novos grupos sociais, mas não aos novos conhecimentos. Por isso exclui os que ignoram o conhecimento que ela valoriza e, assim, entende que a democratização é massificação do ensino. A escola não cria a possibilidade de diálogo entre diferentes instâncias epistemológicas, não se abre a novos conhecimentos que, até então, não couberam nela. (MANTOAN, 2006, p. 15).
}

Desse modo, percebe-se que a escola é um lugar para refletir e aprender sobre muitos assuntos, e o ato de excluir não deveria fazer parte da rede de ensino, pois todos têm ou deveriam ter os mesmos direitos. A questão em destaque aponta que os alunos percebemse fora do padrão que a sociedade impõe (na idade "certa" e alfabetizados) e acabam saindo Saberes Pedagógicos, Criciúma, v. 3, n³, Edição Especial 2019.- Curso de Pedagogia - UNESC 
das escolas. Dessa forma, a evasão escolar tem sido frequente na Educação de Jovens e Adultos, fazendo com que o processo de ensino-aprendizagem seja interrompido, sem prazo para dar continuidade, levando ao fracasso escolar (MANTOAN, 2006).

E quando voltam à escola, os jovens e adultos têm que ultrapassar muitas barreiras preconceituosas, geralmente para alcançar seus objetivos, aprender a ler e escrever. Assim, uma proposta pedagógica bem trabalhada faz com que os alunos estejam dispostos para a aprendizagem, prevalecendo uma atitude positiva aos estudantes (BRASIL, 2002).

Sendo assim, cabe à escola fazer a inclusão dos alunos que se sentem excluídos do ambiente escolar. E a integração é o meio para esse elo, com a inserção do aluno ou um grupo de alunos na instituição de ensino. Como situa Mantoan (2006, p. 19), "o mote da inclusão, ao contrário, é não deixar ninguém no exterior do ensino regular, desde o começo da vida escolar." Ou seja, todos os alunos têm direito à educação, independentemente de sua escolaridade e faixa etária.

A Proposta Curricular de Educação para Jovens e Adultos faz esse mesmo elo, aproximando ainda mais os alunos jovens e adultos que voltam às escolas, pois são mais resistentes a expor suas ideias, quem sabe pela timidez ou pelo fato de não terem a clareza de que possuem conhecimentos escolares, mas quando reconhecem dão um grande passo para a aprendizagem. Dessa forma, o professor pode criar um espaço escolar confortável e acolhedor para os alunos, dedicando atenção maior a esses casos, estimulando-os a exporem suas ideias por meio da linguagem oral ou dramática, do desenho, escrita, dentre outras (BRASIL, 2001).

Mas além da escola os professores também podem incluir os alunos na sala de aula, como aborda Jacques (2017, p. 132):

O profissional da educação de jovens e adultos, em especial o professor de sala de aula, torna-se imprescindível que ele se desprenda de preconceitos, de estigmas, de representações sociais pré-estabelecidas e acredite que alfabetizar sujeitos com idade escolar avançada é possível, e, acreditando nisso, invista em práticas educativas específicas ao público-alvo.

O professor como intermediador do conhecimento pode fazer a inserção dos alunos que se sentem excluídos, pois a escola é um direito para todos e cada particularidade, quando trabalhada em conjunto, faz com que os demais alunos percebam que as diferenças 
existem e são normais. Há certa diferença entre o aluno jovem e o adulto que estão na mesma classe escolar. O aluno jovem, muitas vezes, não se preocupa se vai ou não acertar a pergunta feita pela professora, dividindo com os colegas seu ponto de vista. Já o adulto manifesta insegurança, medo de se expor ao ridículo e fala ainda ser incapaz de aprender e quando se trata de mudanças é mais resistente. Desse modo, acontece a autoexclusão. O aluno se sente inferior aos demais, achando estar no lugar errado, e acaba se isolando, deixando de interagir com a turma (BRASIL, 2002).

A falta de acolhimento aos alunos pode ser originada, na maioria das vezes, pelo fato da escola não reconhecer a diversidade da população atendida. Esses alunos estão inseridos na sociedade como a minoria e têm suas particularidades e, em muitos casos, fazem parte da classe trabalhadora. O professor precisa estar atento para não olhar essa especificidade como algo ruim, mas entendê-la e respeitá-la para que os alunos se sintam inseridos na comunidade escolar (BRASIL, 2002).

Reconhecer a diversidade e buscar formas de acolhimento requer da equipe escolar disponibilidade, informações, discussões e, muitas vezes, ajuda de outro profissional fora da escola para ajudar na inclusão desses alunos. Quando a escola está disposta a recebêlos, tem que considerar as características de cada um, diferença de idade, local onde mora, classe social, se trabalha ou não, para a partir destes quesitos desenvolver um projeto educativo que contemple todo e qualquer tipo de aluno, inserindo-os cada vez mais no ambiente escolar e garantindo a sua aprendizagem e permanência (BRASIL, 2002).

O processo de acolhimento dos alunos da EJA não é um papel fácil, pois envolve a emoção, motivação, valores e atitudes, responsabilidades e compromissos. Segundo a Proposta Curricular para a Educação de Jovens e Adultos,

O acolhimento ao aluno envolve tanto a valorização dos conhecimentos e da forma de expressão de cada um como seu processo de socialização, levado em conta, nas situações de ensino e aprendizagem, dúvidas e inquietações, realidades socioculturais, jornada de trabalho e condições emocionais decorrentes de conclusão escolar (BRASIL, 2002, p. 88).

O acolhimento também está nas oportunidades dadas aos alunos. Estimular, valorizar, reconhecer e oferecer subsídios para elevar as produções deles, onde se reconhecem como autores da cultura, capazes de propor, criar e participar das atividades (BRASIL, 2002). Saberes Pedagógicos, Criciúma, v. 3, n³ , Edição Especial 2019.- Curso de Pedagogia - UNESC 


\section{METODOLOGIA, APRESENTAÇÃ̃ E ANÁLISE DE DADOS}

Há muitos casos que determinam a realização de uma pesquisa. Desse modo, pode-se afirmar que a pesquisa é o procedimento racional e sistemático, onde o objetivo é proporcionar respostas aos problemas que são propostos, ou seja, a pesquisa é requerida quando as informações não são suficientes para responder ao problema (GIL, 1991).

A abordagem desta pesquisa é qualitativa, pois foca no caráter subjetivo do que está sendo analisado, nesse caso os alunos da Educação de Jovens e Adultos. Por meio dela, foram estudadas as particularidades e experiências individuais de cada aluno para entender como foi o processo de ensino e aprendizagem deles.

A natureza da pesquisa é básica. Esta por sua vez traz a necessidade de contribuir para a formação dos jovens e adultos que voltaram para as escolas depois de muito tempo e lutaram para ter seus lugares garantidos na sociedade. Em vista disso, percebe-se a importância de uma pesquisa nesse nível de escolaridade para mostrar uma realidade quase esquecida pela sociedade, tanto por descaso das coordenações políticas quanto pela própria comunidade, que fecham os olhos e fingem estar tudo certo.

A pesquisa está dentro dos objetivos descritivo. Sendo assim, são descritas as características dos alunos em seus graus de aprendizagem, visando à coleta de dados e observação. Além disso, pode-se identificar a importância desta pesquisa, pois contém informações que farão com que as pessoas repensem nas condições dos alunos da EJA, pois todos tiveram os seus motivos para sair e voltar à escola. Que os olhares diferenciados se tornem "normais" quando se tratam de seres humanos.

O procedimento se dá através da pesquisa de campo, onde foram realizadas investigações em que, além do estudo bibliográfico, a coleta de dados foi feita em uma sala de Educação de Jovens e Adultos, séries iniciais. Depois de uma apresentação básica do acadêmico, foi perguntado quem queria contribuir com a entrevista e 07 alunos matriculados na escola se propuseram a responder, sendo 04 do sexo feminino e 03 do sexo masculino, com a faixa etária que vai dos 33 a 57 anos de idade e com diferentes profissões. Com isso, a pesquisa foi realizada no período noturno em uma escola da rede municipal da cidade de 
Criciúma/SC. Para preservar a ética da pesquisa, os alunos foram nomeados em A1, A2, A3, A4, A5, A6 e A7.

A sala de aula foi escolhida conforme o grau de aprendizagem dos alunos, pois o tema da pesquisa visa observar o processo de ensino e aprendizagem dos alunos em suas formações, ou seja, como eles se alfabetizaram e como se perceberam no mesmo processo de ensino. Sendo assim, a coleta de dados usada para realizar essa pesquisa foi em forma de roteiro de entrevista semiestruturada.

\subsection{Dificuldades, quem não tem? Respeito, todos querem!}

Todos nós temos algum tipo de dificuldade, seja na vida profissional ou pessoal. As dificuldades também acompanham os alunos jovens e adultos que fizeram parte desta pesquisa. Dificuldades que, por muitas vezes apagam o sonho daqueles que não tiveram oportunidades de concluir os estudos na idade certa. Por conta disso, alguns alunos relataram que já sofreram algum tipo de preconceito por serem analfabetos e na maioria dos casos vem da própria família.

A dificuldade para os alunos da EJA é vista como uma barreira que impede de ultrapassá-la, fazendo-os desistir mais uma vez da escola. Mas que ainda percorrem o caminho em busca da realização de um sonho, enfrentando todas as barreiras para chegar ao objetivo final, a alfabetização.

$\mathrm{O}$ aluno A1 tem a consciência do que lhe aflige, mas manteve a cabeça erguida e continuou no seu processo de alfabetização. Ele disse que tem dificuldades em juntar as letras e que algumas letras ainda não conhece, mas sabe escrever seu nome e poucas palavras simples, como "pato, dado, casa, bola...”. Terminou dizendo que não está muito bom na leitura. Mas isso é normal para quem ainda está em processo de alfabetização e, na maioria das vezes, esquece letras quando escreve alguma palavra.

De acordo com Carvalho (2009, p. 87), “[...] os alunos principiantes, que apenas começaram a estabelecer relações entre letras e sons, cometem erros de troca ou omissão de 
letras, como mto por muito, vedade por verdade, falado por falando etc. [...]". Casos frequentes e relevantes, que vão do "erro" 3 " ao acerto quando menos esperam.

Além disso, essas dificuldades iniciais são normais, até porque são alunos que frequentaram pouco a escola ou não tiveram a oportunidade de passar por ela. Dificuldades que dão o ponto de partida para conhecer o novo, ir além do que sabem e transformar suas vivências em algo prazeroso. Por outro lado, os alunos também aprendem com os erros e percebem que, em muitos casos, o fazer é muito mais válido do que o certo, pois quando você tenta, independentemente da forma como faça, é o resultado que dará o real significado.

Nessa mesma linha de dificuldades, outros alunos pesquisados contribuíram dizendo que sentem dificuldades na leitura, em juntar as letras para ler. A3 revelou: "Copio do quadro, mas se apaga e pede para eu escrever no caderno, não consigo." Ele relatou que na leitura tem um pouco mais de facilidade.

Já A6 disse que dá vontade de desistir por achar que está no grau de dificuldade igual quando voltou à escola. Referente ao questionamento feito sobre se tinha alguma dificuldade em aprender a ler e a escrever, respondeu: "Bastante. A gente via todos passando na frente e a gente no mesmo lugar. Dava vontade de desistir, mas persistia e queria continuar."

Ou seja, o desejo de vencer as próprias expectativas fez com que não desistisse de seu sonho, apenas se reestabeleceu e continuou firme no seu processo de alfabetização. Por outro lado, alguns alunos não sentiram tantas dificuldades com a leitura e escrita, pois já entraram na EJA sabendo ler e escrever, quem sabe, ou seja, tiveram oportunidades de pelo menos aprender o básico.

Outras dificuldades apontadas pelos alunos pesquisados estão em pegar o ônibus ou chegar a um determinado endereço, por não saber ler as informações descritas nas placas de localização. Essas situações são constantes nas vidas dos alunos da EJA, e percebem a diferença quando começam a juntar as primeiras letras e iniciam a leitura.

A1 relatou que viajou para a cidade de Pernambuco de avião e sentiu dificuldades para ler as placas de localização no aeroporto. Depois que entrou na EJA, começou a juntar algumas letras e formar palavras. Ele afirmou: "Lendo agora, viajar vai ficar maravilhoso,

${ }^{3}$ A palavra "erro" é entendida, como possibilidades de acertos escritos.

Saberes Pedagógicos, Criciúma, v. 3, n³, Edição Especial 2019.- Curso de Pedagogia - UNESC 
porque conseguirei ler as placas. No meu trabalho já consigo juntar as letras e ler as placas." Ou seja, cada passo dado é uma conquista para os alunos que fizeram parte da pesquisa.

Em conformidade com o exposto:

Saber ler e escrever, saber utilizar a leitura e a escrita nas diferentes situações do cotidiano são, hoje, necessidades tidas como inquestionáveis tanto para o exercício pleno da cidadania, no plano individual, quanto para a medida do nível de desenvolvimento de uma nação, no nível sociocultural e político. É, portanto, dever do Estado proporcionar, por meio da educação, o acesso de todos os cidadãos ao direito de aprender a ler e a escrever, como uma das formas de inclusão social, cultural e política e de construção da democracia (MORTATTI, 2004, p. 15).

Outra atividade prática social dos alunos entrevistados é ir fazer as compras do mês no supermercado. Depois que estão na escola e conseguem ler, tudo se torna mais fácil, pois já reconhecem algumas letras e palavras, e assim passam a ter mais autonomia na escolha de um produto. A2 percebeu essa diferença: "Quando não sabia ler, ia ao supermercado e identificava os produtos pelos desenhos. Depois tudo ficou melhor com a leitura." Percebe-se que as atividades diárias ficam menos complicadas depois que os alunos se alfabetizam.

Nessa mesma linha de aprendizagem, A3 complementou dizendo que estar alfabetizado facilitou para pegar o ônibus. "Agora no supermercado consigo ler as plaquinhas. Pego a bíblia para ler e em algumas partes eu entendo, em outras não. Quando estamos aprendendo, o cara fica feliz." Para reiterar, A5 comentou sobre o caos de pegar ônibus também. "Para pegar ônibus no terminal é fácil porque ele fica parado, mas quando é fora, no bairro, é difícil." É nítido o prazer que os alunos pesquisados têm em usar o que aprenderam na escola nas atividades diárias.

Nessa mesma linha de raciocínio, Soares (2003, p. 37) discorre sobre o assunto:

Socialmente e culturalmente, a pessoa letrada já não é a mesma que era quando analfabeta ou iletrada, ela passa a ter uma outra condição social e cultural - não se trata propriamente de mudar o nível ou a classe social, cultural, mas de mudar seu lugar social, seu modo de viver na sociedade, sua inserção na cultura - sua relação com os outros, com o contexto, com os bens culturais torna-se diferente.

O que as pessoas não percebem é que os alunos pesquisados tiveram seus motivos para sair da escola muito cedo, mas que agora, mesmo com suas dificuldades, querem 
aprender o básico para somar em suas vidas. As diferenças podem ser culturais, sociais, religiosas e mais, como aborda Mantoan (2006, p. 14): “A diversidade humana vem sendo cada vez mais desvelada e destacada e se tornando condição imprescindível para entendermos como aprendemos e como compreendemos o mundo e a nós mesmos."

Quando se trata de alunos analfabetos, se "viram" em casa como conseguem, como por exemplo A6, que argumentou: "Agora mexo no celular, porque antes chamava a filha para ler as mensagens. Leio a receita de um bolo; no supermercado agora olho os preços e a validade; agora mexo sozinha e mando mensagem no celular." Ou seja, utiliza da leitura e escrita para resolver as demandas sociais.

\subsection{Letramento: das letras para o mundo}

A palavra letramento ultrapassa as linhas escritas de um papel, ela vai das letras à interpretação que as pessoas fazem. Entender o significado das palavras escritas, muitas vezes, faz com que as pessoas se imaginem no contexto que estão lendo e percebam que o mundo não é só feito de palavras, mas também de sentimentos, emoções, descobertas. E, claro, da escrita, esta que muda a vida das pessoas que conseguem juntar as letras e ler a palavra, saindo das letras para o mundo, onde se percebem alfabetizados nos pequenos detalhes e se engrandecem no ponto de partida para uma vida cheia de aprendizagens e realizações.

Com base nisso e na pesquisa, constatou-se que muitos alunos pesquisados não chegaram ao $5^{\circ}$ ano do ensino fundamental por terem que deixar a escola para cuidar dos irmãos enquanto os pais trabalhavam na roça para sustentar a família ou abandonaram a escola para trabalhar. A5 relatou: "Estudei até a metade do $1^{\circ}$ ano, meus pais trabalhavam na roça e eu cuidava dos irmãos."

Como abordam Galvão e Pierro (2013, p. 16), "a ampla maioria dos analfabetos é constituída por pessoas oriundas do campo, de municípios de pequeno porte, nascidas em famílias numerosas e muito pobres, cuja subsistência necessitou da mão de obra de todos os membros desde cedo." Com isso, torna-se nítido que a falta de oportunidade para estudar, muitas vezes, é por conta do trabalho dos pais, que não têm com quem deixar os filhos mais Saberes Pedagógicos, Criciúma, v. 3, n³ 3, Edição Especial 2019.- Curso de Pedagogia - UNESC 
novos e os mais velhos ficavam de babás, deixando a escola para um futuro próximo. É nesse sentido que

\begin{abstract}
A LDBEN n. ${ }^{\circ}$ 9.394/96 prevê que a educação de jovens e adultos se destina àqueles que não tiveram acesso (ou não deram continuidade) aos estudos no Ensino Fundamental e Médio na faixa etária de 7 a 17 anos, e deve ser oferecida em sistemas gratuitos de ensino, com oportunidades educacionais apropriadas, considerando as características, interesses, condições de vida e trabalho do cidadão. (BRASIL, 2002, p. 17).
\end{abstract}

Mesmo as leis assegurando os direitos das crianças de estarem na escola e longe do trabalho, os pais iam contra elas e retiravam os filhos da escola para ajudar nas despesas domésticas, retardando o aprendizado dos filhos naquele momento.

Por esse motivo, o trabalho pesado marcava a vida dos pesquisados da EJA, pois muitos abandonavam a escola para ajudar os pais nas roças. A6 afirmou: "Eu nunca consegui ler e escrever, era só ir para a roça." Mas teve o incentivo das filhas que são professoras para retomar os estudos. "É muito ruim não saber ler, pois quer pegar um ônibus ou chegar a algum lugar não consegue e quando pergunta para alguém, até dão informação errado. Meu sonho é ler e escrever e se Deus quiser receber um diploma." (A6).

Além da aprendizagem, os alunos voltaram à escola para realizar seus sonhos, seja profissional ou pessoal. É o caso de A7: "Voltei à escola para realizar meu sonho, ser professora. Acho a profissão de vocês muito bonita." Com isso, reafirmo que os alunos entrevistados querem algo de novo para suas vidas e isso começa pela escola. Do mundo das letras para uma sociedade igualitária e justa com aqueles que um dia foram olhados com dó, mas que aos poucos alcançam seus objetivos, com responsabilidade e esperança em aprender cada vez mais na condição de alunos e se respeitarem enquanto seres humanos.

Diante do exposto, surge um questionamento: por que os alunos da EJA resolveram voltar à escola? A resposta é muito pessoal, pois cada um tem seu motivo particular para continuar no caminho da educação e alcançar seus objetivos. Com isso, A1 respondeu: "Porque tenho inveja do cara que pega um livro e lê." Ele relatou que demorou aproximadamente três horas para ler que o médico era às 15h00min, mas que ficou feliz. Assim, todos os alunos entrevistados voltaram à escola com o objetivo de sair alfabetizados, 
mesmo que saiam na condição de analfabetos funcionais, ou seja, escrevem e leem textos curtos.

Os alunos pesquisados voltaram à escola para serem alfabetizados e, dessa forma, as suas expectativas com a escolaridade são grandes. Em vista disso, Mantoan (2006, p. 13) comenta que os alunos

[...] despontam nos diferentes âmbitos das atividades humanas e que num mesmo momento começam a transgredir, a ultrapassar as fronteiras do conhecimento, dos costumes, das artes, inaugurando um novo cenário para as manifestações e atividades humanas, a qualquer custo, porque tem clareza do que estão propondo e não conseguem se esquivar ou se defender da força das concepções atualizadas.

A oportunidade em novos trabalhos e para crescer profissionalmente na empresa em que já trabalham é outro motivo apontado pelos alunos pesquisados para voltarem à escola. "Quero terminar os estudos para me formar em Analista Imobiliário (vendedor). Ganhar melhor, emprego melhor." (A2).

Além do trabalho, os alunos voltaram à escola com o intuito de ajudar os familiares em suas atividades/tarefas. Como dizem Galvão e Pierro (2013, p. 58), “[...] embora não seja o único espaço social onde as pessoas podem se alfabetizar, a escola é a instituição à qual se atribui e de quem se cobra explicitamente a função de ensinar a ler e escrever."

Com isso, A5 disse que voltou por causa da irmã, que queria ensinar a filha que estava no $4^{\circ}$ ano do ensino fundamental a ler e resolveu entrar na EJA para ajudar na alfabetização da menina. Desse modo, as irmãs voltaram aos estudos. "Resolvemos entrar para aprender qualquer coisa e depois ensinar a filha da minha irmã. Eu quero pelo menos ler um pouquinho para ler as coisas." (A5).

A EJA abriu muitas portas para que os alunos pesquisados pudessem concretizar seus sonhos. O objetivo da modalidade é "[...] um olhar diferenciado para seu público, acolhendo de fato seus conhecimentos, interesses e necessidades de aprendizagem. Pressupõe também a formulação de propostas flexíveis e adaptáveis às diferentes realidades. [...]" (BRASIL, 2002, p. 87). 
A3 afirmou que o tempo vai passando e as coisas vão ficando cada vez mais difíceis, e que voltou à escola para aprender a ler e escrever. "Não importa se vou ou não subir de cargo, o que importa é que vou saber ler e escrever." (A3). Vemos isso como a determinação de alguém que quer algo de novo para sua vida. Por outro lado, vemos alunos que querem ser "alguém" perante a sociedade, como o caso de A4. "Voltei à escola para me formar e ser alguém na vida. Não quero ficar sempre limpando a casa dos outros, não desmerecendo. Estudando tu consegues um emprego melhor, vida melhor."

Se não fosse o suficiente os alunos jovens e adultos pesquisados enfrentarem as barreiras por serem analfabetos, ainda enfrentam o preconceito por estarem no processo de alfabetização e letramento. Como sabemos, "a alfabetização é considerada um dos pilares da cultura contemporânea, pelo valor que a leitura e a escrita adquiriram no modo de vida nas sociedades urbano-industriais permeadas pela ciência e tecnologia. [...]" (GALVÃO; PIERRO, 2013, p. 13).

Infelizmente, palavras e ações demonstram o quanto às pessoas ainda julgam sem ao menos saber o motivo de cada pessoa e desanimam aqueles em que, dentro do peito, ainda está acesa a chama da esperança por aprender a juntar as letras e escrever o próprio nome. Que momento lindo, emocionante saber escrever o nome completo! Para os alfabetizados isso é muito fácil, pois tiveram seus direitos respeitados e aprenderam no tempo certo, mas para os alunos da EJA isso é uma dádiva, embrulhado em papel de seda onde ninguém pode tocar ou arrancar das mãos como se os sonhos fossem impossíveis de se tornarem reais. Em suas vidas o lápis contorna a linha do coração e a borracha apaga as mágoas trancafiadas no passado.

Contudo, o apoio familiar conta muito para que os alunos permaneçam firmes na escola, mas, infelizmente, não é isso que acontece, em casos específicos na educação de jovens e adultos. Alguns alunos pesquisados relataram que parentes próximos questionavam o motivo para retornarem à escola. A6 contou que os parentes falavam: "Vai ficar em casa, assistir novela, sair com esse frio, não aprende mais nada", ou seja, desmotivando e descrendo na capacidade dela.

A7 emendou a fala da colega quando questionada se sofria preconceito por ir à escola e ela respondeu com os olhos brilhando: "Preconceito não, só questionamento da minha irmã porque voltei à escola", mas respondeu dizendo "que ninguém sabe tudo, que Saberes Pedagógicos, Criciúma, v. 3, n³, Edição Especial 2019.- Curso de Pedagogia - UNESC 
aprendemos uns com os outros." Uma prova que eles se respeitam e se gostam, ajudando quando preciso.

Além disso, o preconceito tortura os alunos por dentro e vai corroendo aos poucos, alguns não resistem e saem da escola. A5 comentou: "Mas a gente tem vergonha por não saber ler e escrever, mas não pelos outros, pela gente. E as minhas irmãs que tiveram oportunidade de estudar não aproveitam, eu que queria ir à escola não deu”. Nessa mesma linha de raciocínio, sobre educação, Mortatti (2004, p. 29) comenta:

\begin{abstract}
A educação (do latim educativo, educere - conduzir para fora de) pode ser definida como uma atividade específica e constitutivamente humana que tem por finalidades a formação, ou seja, o desenvolvimento das virtualidades próprias do ser humano, considerando-se sua capacidade de ensinar e aprender, em diferentes situações, espaços e momentos da vida. Considerando também tanto a necessidade de transmissão da tradição - de que são portadores os adultos - às novas gerações, visando à sua inserção no mundo público da cultura quanto de transformação na ordem política, social, cultural e econômica, visando à criação, sobretudo por parte dos "novos", de um futuro que se considera melhor [...].
\end{abstract}

Mas o contrário também acontece na EJA, alunos que já sabem ler e escrever, mesmo que seja pouco, voltam à escola para completar os anos escolares. Quando crianças "foram à escola por períodos curtos e descontínuos, onde realizaram aprendizagens pouco significativas, e vivenciaram experiências de fracasso, castigo e humilhação." (GALVÃO; PIERRO, 2013, p. 16). Relacionando com o que foi dito, A7 contou que depois de 37 anos voltou à escola. "Em casa pego um livro para ler, leio a bíblia, mensagens no celular do marido", ou seja, o aprendizado é ainda melhor quando os alunos usam suas atividades de casa para reforçar o que aprendem na escola.

Em consequência disso, alguns alunos pesquisados não sofreram nenhum tipo de preconceito por serem analfabetos, pelo contrário, até receberam apoio. Isso acontece com a minoria, em que realmente tem alguém que incentiva o estudar. Deste modo, A1 contou: "Meu pai bebia e por isso não tive condições de estudar, então tive que largar os estudos para colocar comida dentro de casa." Mas reiterou sobre seu trabalho: "Na empresa, o chefe pediu para eu voltar a estudar. Tive que renovar a carteirinha e não consegui.” Então, percebe-se que muitas coisas se passam diante de seus olhos e, na maioria das vezes, não enxergam 
porque não estão dentro do padrão que a sociedade impõe. "Na EJA eles me dão força, não querem que eu desista. Não sofro preconceito por estar aqui.”(A1).

Já A3 comentou: "Não sofria preconceito, mas ficava mais quieto, escondido no meio de quem sabia ler e escrever." Mas completa com uma frase que ainda persiste na sociedade: "Já perdi muitos empregos por não saber ler, pois não conseguia preencher as fichas." Realidade que assusta, mas que persiste em acompanhar os alunos jovens e adultos quando ainda analfabetos.

Diante do pressuposto, os alunos jovens e adultos pesquisados mostraram-se abertos para compartilhar as suas histórias, de certa forma, tristes e amargas, onde o que importa, para muitas pessoas, é seu nível de escolarização e não o seu desenvolvimento epistêmico. Não é de importância uma escolarização completa onde o indivíduo não respeita o próximo por suas indiferenças, seja ela qual for, sem ao menos saber da sua vivência.

Muito se tem falado em equidade. Mas que equidade se tem falado? Uma vez que ações discriminatórias e preconceituosas ainda persistem em nossa sociedade? Não vemos equidade na educação, principalmente na EJA, onde o principal objetivo é aprender a ler e escrever o nome próprio. Ah, como é mágico saber escrever o nome! Usar as letras para desenvolver palavras, sejam concretas ou não, pois no brincar com as letras os alunos também aprendem. Um mundo que passa das letras para as palavras. Das palavras às frases e das frases para a vida! Dessa forma, um dia, quem sabe, todos terão o seu devido valor, pois respeito todos querem, e escrever e ler todos saberão.

\section{CONCLUSÃO}

A partir deste estudo, pode-se perceber que o analfabetismo ainda é muito presente na sociedade, mesmo com tantos meios de comunicação anunciando campanhas nacionais para sua erradicação. Os dados são gritantes e deixam o Brasil entre os países com mais pessoas analfabetas, segundo dados do IBGE/2016. Dados alarmantes que nos preocupam, ainda mais quando o apoio que era para começar em casa não acontece. Dessa forma, desmotivam aqueles que querem ser alfabetizados e letrados e acabam se trancando em casa com vergonha de suas especificidades.

Saberes Pedagógicos, Criciúma, v. 3, n³ 3, Edição Especial 2019.- Curso de Pedagogia - UNESC 


\section{SABERES PEDAGÓGICOS}

Revista do Curso de Graduaçāo de Pedagogia - Unesc

ISSN 2526-4559

Este estudo demonstrou que muitos alunos que foram pesquisados se perceberam alfabetizados e letrados nos momentos mais simples e se envaideceram quando conseguiram ler ou escrever palavras de relação biunívocas, ou seja, palavras que correspondem a um único fonema. Ou muito mais do que isso, quando conseguiram se locomover de um lugar ao outro sem pedir ajuda a ninguém para ler as placas de localização em terminais de ônibus ou aeroportos. Atividades sociais como essas, aliadas à ida ao supermercado, ajudar os filhos nas tarefas escolares, mexer no celular e dentre outros, modificaram a vida dessas pessoas para melhor, fazendo com que cada vez mais seus processos de alfabetização e letramento se concretizassem com êxito.

Diante desta pesquisa surge a emoção. A emoção de acreditar em nossos potenciais, na capacidade de alcançar aquilo que mais queremos. Isso tudo é muito mais evidente quando os alunos da educação de jovens e adultos escrevem pela primeira vez seus nomes, ou quando conseguem juntar as letras para formar uma palavra. A emoção deles toma conta do momento e transborda o coração de quem está acompanhando, pois são mãos calejadas do trabalho que seguram um lápis em movimentos que se repetem para dar a perfeição de uma letra, ou as mesmas que pegam a borracha para apagar a marca deixada pelo rabisco descontente. Expressões fascinantes de cada acerto e multiplicadas pelo erro, onde percebem que a partir dele conseguem escrever/ler corretamente e se dão por satisfeitos diante da possível dificuldade, que mais uma vez foi vencida.

Além das dificuldades superadas, o presente artigo traz pontos referentes ao preconceito que os alunos da EJA enfrentaram para voltar à escola. Em muitos casos, não têm o apoio da família e avançam sozinhos, se apoiando na vontade de vencer e realizar mais um sonho. No momento que chegam à sala de aula, percebem que não estão sozinhos, que todos buscam pelo mesmo objetivo, a alfabetização, e se ajudam para vencer mais um obstáculo que a vida impôs. Sorrisos envergonhados, olhos cansados e noites enluaradas descrevem o sucesso de estar concluindo mais uma etapa de suas vidas.

Um questionamento surge perante a vontade dos alunos pesquisados terem voltado à escola: por que o sucesso incomoda as pessoas? Sim, sucesso! Alunos que saem de suas casas diariamente em busca do conhecimento são tratados como o diferente, ridículo, perda de tempo, como se fosse tarde para aprender e viver. E pode-se perceber que não, nunca 
é tarde para fazer o que se tem vontade. Os pesquisados têm sonhos como qualquer outra pessoa e cabe à escola dar esse espaço para a concretização deles.

Conclui-se que a educação de jovens e adultos tem muito para avançar, mas que tem um trabalho mais que importante na vida das pessoas, pois ela parte do princípio, o respeito e a valorização dos alunos, todos com suas dificuldades e particularidades. A EJA é transformadora, encantadora e única, envolve aqueles que por ela passam e desmistifica o rótulo que a sociedade impõe, desbancando o preconceito e a autoestima baixa, fazendo com que os alunos percebam os seus valores e que podem ser e fazer o que quiserem. Com isso é o legado que fica: a educação transforma o coração daqueles que estão abertos ao conhecimento.

\section{REFERÊNCIAS}

BRASIL. Ministério da Educação. Secretaria da educação fundamental. Proposta curricular para educação de jovens e adultos: segundo segmento do ensino fundamental ( $5^{\mathrm{a}}$ a $8^{\mathrm{a}}$ série). Brasília: secretaria de educação fundamental, 2002. 148 p.

BRASIL. Ministério da Educação e do Desporto. Educação para jovens e adultos - ensino fundamental: proposta curricular - $1^{\circ}$ segmento. São Paulo: Ação educativa; Brasília: MEC, 2001. 239 p.

CARVALHO, Marlene. Primeiras letras: alfabetização de jovens e adultos em espaços populares. São Paulo: Editora Ática, 2009. 176 p.

GALVÃO, Ana Maria de Oliveira; PIERRO, Maria Clara de. Preconceito contra o analfabeto. 2. ed. São Paulo: Cortez Editora, 2012. 125 p.

GIL, Antonio Carlos. Como elaborar projetos de pesquisa. São Paulo: Atlas, 1991.

IBGE. PNAD Contínua 2016: 51\% da população com 25 anos ou mais do Brasil possuíam apenas o ensino fundamental completo. Disponível em: https://goo.gl/mGpeJj. Acesso em: 13 mar 2018.

JACQUES, Izabel Cristina Maffioletti; CASAGRANDE, Samira. Analfabeto e preconceito: uma relação velada na sociedade. Revista Saberes Pedagógicos, Fundação Educacional de Criciuma- FUCRI [s.1.], v. 2, p.121-136, 1 jun. 2017. Disponível em:

http://dx.doi.org/10.18616/rsp.v2i0.3395. Acesso em: 28 fev 2018.

Saberes Pedagógicos, Criciúma, v. 3, n³, Edição Especial 2019.- Curso de Pedagogia - UNESC 


\section{SABERES PEDAGÓGICOS}

Revista do Curso de Graduaçāo de Pedagogia - Unesc

ISSN 2526-4559

KLEIMAN, Angela B.. Modelos de letramento e as práticas de alfabetização na escola. In: KLEIMAN, Angela B. (Org.). Os significados do letramento: uma nova perspectiva sobre a prática social da escrita. Campinas: Mercado de Letras, 1995. p. 15-61.

MANTOAN, Maria Tereza Eglér. Inclusão escolar: o que é? por quê? como fazer?. 2. ed. São Paulo: Moderna, 2006. 63 p.

MORTATTI, Maria do Rosário Longo. Educação e letramento. São Paulo: Unesp, 2004. $136 \mathrm{p}$.

ROJO, Roxana. Letramentos múltiplos, escola e inclusão social. São Paulo: Parábola Editorial, 2009. 128 p.

SOARES, Magda. Letramento: um tema em três gêneros. 2. ed. Belo Horizonte: Autêntica Editora, 2014. 124 p.

SOUSA, João Paulo Aguiar de. Analfabetismo no Brasil: história, realidade e preconceito. ABEP. Águas de Lindóia/SP. 2012. Disponível em: https://pt.scribd.com/document/180638732/4-Analfabetismo-No-Brasil. Acesso em: 28 fev 2018.

TFOUNI, Leda Verdiani. Letramento e alfabetização. 5. ed. São Paulo: Cortez, 2002. 104 p.

Recebido: 26/05/2019

Aprovado: 01/08/2019

Publicado: 20/09/2019

Saberes Pedagógicos, Criciúma, v. 3, n³, Edição Especial 2019.- Curso de Pedagogia - UNESC 